\title{
ІНФОРМАЦЙНА ПІДТРИМКА УПРАВЛІННЯ ІННОВАЦІЙНИМ РОЗВИТКОМ ВИРОБНИЦТВА В УМОВАХ НЕВИЗНАЧЕНОСТІ
}

\begin{abstract}
Обтрунтовано методологічний підхід до кількісної оцінки вхідної інформації при управлінні інноваційним розвитком виробничтва в умовах невизначеності, як різниия апріорної та апостеріорної ентропї. Створено структуризацію інформаційних потреб $i$ засобів забезпечення інформації управління як стратегічного ресурсу динаміки протікання виробничих процесів. Встановлені базові операції підтримки прийняття рішень, які формують оптимальну стратегію управління $і$ включають оцінку потрібної кількості інформачї, діагностику інформачійної ситуації, вибір критеріїв оптимальності становлення правила відбору, відображають функиіональні особливості виробничої діяльності $i$ сприяють формуванню і нарощуванню ї̈ інноваційного потенціалу.
\end{abstract}

Ключові слова: інновачійний розвиток, невизначеність, управління, інформачійній супровід, ентропія, кількісні оцінки.

Постанова проблеми. Ускладнення задач функціонування підприємств на інноваційній основі, виникнення нових цілей, пріоритетів та ресурсних обмежень ставлять сьогодні дослідження теоретичних та практичних проблем управління інноваційним розвитком у розряд актуальних. При розв'язувані задач управління інноваційним розвитком підприємств в умовах невизначеності однієї 3 основних проблем $\epsilon$ розробка методичних прийомів аналізу та обробки інформації, які дозволяють суттєво підвищити надійність та адекватність прийняття рішень.

Аналіз останніх досліджень і публікацій по позначеній проблемі виявляє постійний інтерес до регулювання виробництва i розробки прикладного інструментарію управління інноваційної діяльності 3 урахуванням функціональних особливостей виробничої діяльності підприємств [1-8]. Загальних рекомендацій по вибору найбільш переважних рішень із множини існуючих альтернатив управління в умовах різноманіття інформаційних ситуацій і управлінських дій для реалізації цілей досягнення економічного росту не існує, тому будь-які кроки в рішенні цієї проблеми надзвичайно корисні.

Формування цілей статті. Метою статті $\epsilon$ розробка методологічних підходів і принципів управління інноваційним розвитком підприємств в умовах невизначеності.

Завданнями статті $\epsilon$ : структуризація інформаційних потреб i засобів підтримки управлінських рішень; визначення необхідної

(C) Гусаріна Наталія Вікторівна, к.е.н., доцент Херсонський національний технічний університет, м. Херсон, тел.: 0997136474, email: gusarina@ukr.net кількості вхідної інформації; встановлення базових операцій підтримки прийняття рішень щодо формування оптимальної стратегії управління.

Опис основного матеріалу досліджень. Реалізація управлінських дій по інноваційному розвитку підприємств в умовах невизначеності, викликаної флуктуаціями зовнішнього середовища, потребує інформаційної підтримки управлінських рішень при виборі стратегії управління.

По своїй структурі ця задача відноситься до задачам множинної оптимізації [1-3].

Загальний обсяг інформації, яка необхідна для аналітичного обгрунтування управлінських рішень щодо посилення інноваційної активності підприємств, потрібен мати кількісну оцінку.

Мірою невизначеності істинного значення вимірюваної величини $\epsilon$ ентропія. Ентропія i кількість інформації взаємопов'язані. В інформаційних системах невизначеність зменшується за рахунок прийнятої інформації.

В управлінні розвитком економічної системи поняття ентропії відноситься до характеристик збору, передачі і обробки інформації.

Ентропія представляє собою міру неорганізованості i невизначеності стану регульованого об'єкту. Чим більше ентропія, тим вище невизначеність i непередбачуваність поведінки виробничого об'єкту. Об'єм інформації I залежить від загальної кількості елементів виробничої системи $n$ і числа станів, в яких може знаходитись кожний з елементів $m$ :

$$
I=n \log _{2} m
$$

Поняття ентропії в теорії інформації використовується як характеристика даного ансамблю повідомлень, котра $\epsilon$ мірою невизначеності: 


$$
H=\frac{I}{n}=-\sum_{i=1}^{m} P_{i} \log _{2} P_{i}
$$

де $P_{i}-$ ймовірність знаходження системи в даному стані

Ентропія системи представляє собою математичне очікування логарифму ймовірності перебування системи в заданому стані $m$.

Статистичний аналіз властивостей джерел інформації полягає у визначеності їі ймовірності $P(a)$ як відношення числа сприятливих результатів $N(a)$ до загального числа ймовірних результатів $N$.

$$
P(a)=\frac{N(a)}{N}
$$

Математичне очікування

одне 3 найважливіших понять математичної статистики i теорії ймовірностей, яке характеризує розподіл випадкових величин. Воно має можливі значення при оцінки ризику i використовується при розробки стратегіï в теорії ігор. Математичне очікування $M[X]$ - це сума множень усіх ймовірних значень випадкових величин $x_{i}$ на ймовірності цих значень $p_{i}$. Середнє значення дискретної випадкової величини дорівнює:

$$
M[X]=\frac{x_{1} p_{1}+x_{2} p_{2}+\ldots+x_{n} p_{n}}{p_{1}+p_{2}+\ldots+p_{n}}=\frac{\sum_{i=1}^{n} x_{i} p_{i}}{\sum_{i=1}^{n} p_{i}}
$$

Практичний інтерес представляє не абсолютне значення ентропіі, а піi зміни. При зменшені ентропії вхідна інформація зростає i, навпаки, при зростанні ентропії падає. Зміна ентропії - головний критерій ефективності інноваційної діяльності. Апріорна та апостеріорна інформація - це зв'язані між собою поняття інформаційного дискурсу, які позначають знання попереднього досвіду i знання, котрі отримала система 3 досвіду їх використання.

Розрахунок апріорного розподілу станів зовнішнього бізнес-середовища можна здійснити шляхом обробки обширного статистичного матеріалу або аналітичними методами, які основані на ймовірнісних уявленнях.

Для подій $x_{1}, x_{2}, \ldots, x_{\mathrm{n}}$, які мають рівний ймовірній стан $1 / n$, величина апріорної ентропії дорівнює:

$$
H_{0}=-n \times \frac{1}{n} \log _{2} \frac{1}{n}=-\log _{2} 1+\log _{2} n
$$

3 урахуванням того, що:

$P_{1}=\frac{N\left(x_{1}\right)}{N}, \quad P_{2}=\frac{N\left(x_{2}\right)}{N}, \quad \ldots, \quad P_{n}=\frac{N\left(x_{n}\right)}{N}$.

формула апостеріорної ентропії має вигляд:

$$
H_{1}=-\left[\begin{array}{l}
P_{1}\left(\log _{2} N\left(x_{1}\right)-\log _{2} N\right)+P_{2}\left(\log _{2} N\left(x_{2}\right)-\log _{2} N\right) \\
+\ldots+P_{n}\left(\log _{2} N\left(x_{n}\right)-\log _{2} N\right)
\end{array}\right]
$$

Нижче приведено розрахунки апріорної $H_{0}$ i апостеріорної $H_{1}$ ентропії і кількості інформації $I$ при заданих значеннях ймовірності появи аналізованих подій. Так для $P_{1}=P_{2}=P_{3}$ i $i=1,2$, 3 апріорна ентропія дорівнює:

$$
\begin{aligned}
& H_{0}=-\left[\frac{1}{3}\left(\log _{2} 1-\log _{2} 3\right)+\frac{1}{3}\left(\log _{2} 1-\log _{2} 3\right)+\frac{1}{3}\left(\log _{2} 1-\log _{2} 3\right)\right]= \\
& =-\left[\log _{2} 1-\log _{2} 3\right]=-[0-1.58496]=1.58496
\end{aligned}
$$

Для значень $\quad P_{1}=0.7, \quad P_{2}=0.2, P_{3}=0.1$, характеризуючих можливий ступінь впливу зовнішнього середовища на функціонування виробничих об'єктів, апостеріорна ентропія дорівнює:

$$
\begin{aligned}
& H_{1}=-\left[\frac{7}{10}\left(\log _{2} 7-\log _{2} 10\right)+\frac{1}{5}\left(\log _{2} 1-\log _{2} 5\right)+\frac{1}{10}\left(\log _{2} 1-\log _{2} 10\right)\right]= \\
& =-\left[\frac{7}{10}(2.80735-3.32193)+\frac{1}{5}(0-2.32193)+\frac{1}{10}(0-3.32193)\right]= \\
& =-[(-0.360206)+(-0.464386)+(-0.332193)]=1.156785
\end{aligned}
$$

Різниця цих значень характеризує зміни ентропіі:

$$
\Delta H=H_{0}-H_{1}=1.58496-1.156785=0.428175
$$

Мірою зняття невизначеності $€$ кількість відсутньої інформації, $I=\Delta H$. Виходячи 3 цього, необхідну кількість інформації для прийняття адекватних управлінських рішень по підвищенню інноваційної активності підприємств можливо визначити як різницю апріорної і апостеріорної ентропії. Це положення являється основою запропонованої інформаційно-ентропійної моделі кількісної оцінки вхідної інформації при прийнятті управлінських рішень по інноваційному розвитку підприємств в умовах невизначеності.

Алгоритм пошуку кількості необхідної інформації при управлінні економічним розвитком підприємств в умовах невизначеності (рис. 1).

Якщо у результаті отриманої інформації невизначеність повністю усунена, то вона дорівнює ентропії, яка мала місце до отримання інформації, тобто інформація дорівнює усуненій ентропії.

Оцінка недостатньої кількості інформації I характеризується наступними параметрами: $m$ число елементів виробничої системи, $n$ - число станів, в яких може знаходиться кожний 3 елементів системи, $p$ - ймовірності знаходження елементів системи у даному стані, $H$ - ентропія системи. 


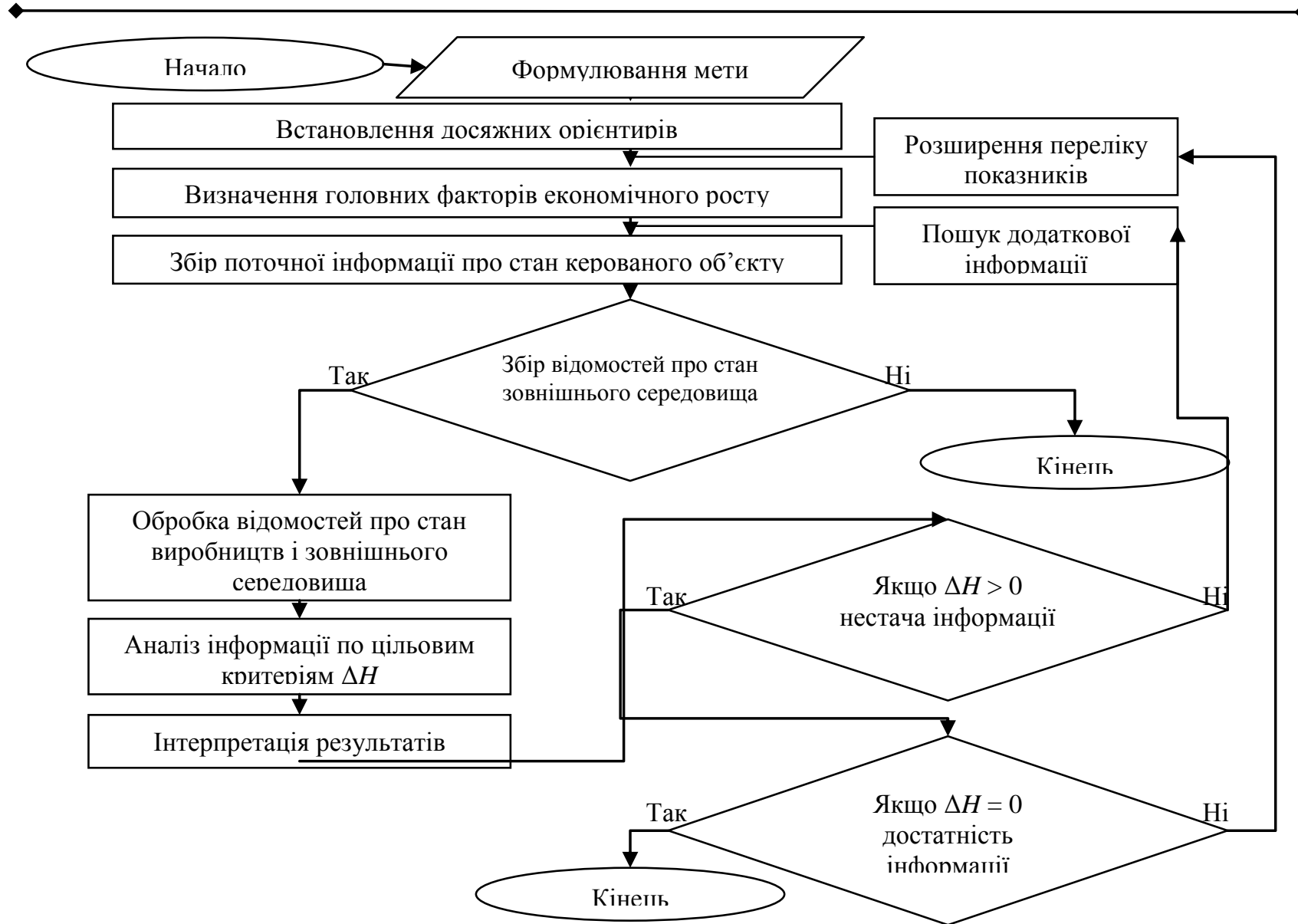

Рис. 1. Алгоритм встановлення необхідної кількості інформації для прийняття адекватних управлінських рішень*

*Розроблено автором

Взаємозв'язок інформаційних ситуацій $I$, рівнів невизначеності $Z$ і управлінських дій $X$ характеризується наступним набором величин: $X-$ множина альтернатив управлінських дій, $Y-$ множина станів виробництва, $P(x)$ - ймовірність впливу зовнішнього середовища, $S$ - простір станів, $\Phi-$ принцип обгрунтування вибору альтернатив, $D$ - обмеження на ресурси, $Q$ - критерії оптимізації.

Ситуація $у \epsilon Y$ потребує діагностики, яка полягає в $\dddot{1}$ виборі 3 множини можливих $Y$. Еволюція результатів управління описується розподілом $P(x)$ в просторі станів $S$. В процесі вибору конкретних числових значень варійованих параметрів моделей управління враховуються тільки допустимі значення, відповідні можливим обмеженням на ресурси $D$. Тоді область допустимих рішень в діагностиці інформаційної ситуації, описується наступним чином:

$$
I=f(X, Y, P(x), S, \Phi, D, Q, Z) .
$$

У ряді економічних завдань при впровадженні інноваційної продукції та розгляді варіантів вкладення капіталу $K$, необхідно враховувати певне значення собівартості продукції $C$. Вибір варіантів вкладення капіталу проводитися за умови, що ймовірності можливих станів господарської діяльності різні і проявляються в різній ступені впливу зовнішнього середовища на загальну результативність інноваційної діяльності.

Ситуаційно-ймовірнісні фактори враховуються в стратегіях $A_{i}$, що визначають ефективність прийняття рішень і представляються у вигляді платіжної матриці $A$. Ї̈і елементами $є: \Pi_{i}$ середньоквадратичні відхилення флуктуацій зовнішнього середовища i $a_{i j}$ - математичні очікування від одержуваного прибутку.

$$
A=\begin{array}{c|cccccc} 
& \Pi_{1} & \Pi_{2} & \ldots & \Pi_{n} & & \\
& a_{11} & a_{12} & \ldots & a_{1 n} & \alpha_{1} & \\
A_{1} & a_{21} & a_{22} & \ldots & a_{2 n} & \alpha_{2} & \alpha_{i}=\min a_{j} \\
A_{2} & \ldots & \ldots & \ldots & \ldots & \ldots & \beta_{j}=\max a_{i} \\
\ldots & a_{m 1} & a_{m 2} & \ldots & a_{m n} & \alpha_{m} & \\
& \beta_{1} & \beta_{2} & \ldots & \beta_{n} & &
\end{array}
$$

Функціональний аналог технологічного процесу управлінням інноваційного розвитку в умовах невизначеності дозволив виділити чотири базових операції підтримки прийняття рішень: оцінку необхідної кількості інформації $X_{1}$, діагностика інформаційної ситуації пов'язана зі структуризацією взаємодії $X_{2}$, вибір критеріїв 
оптимальності, пов'язаних 3 формуванням платіжної матриці і виконанням розрахунків за існуючими алгоритмами для визначення оптимальної стратегії розвитку $X_{3}$, встановлення правил відбору, пов'язаних 3 визначенням рівнів невизначеності $X_{4}$ (рис.2).

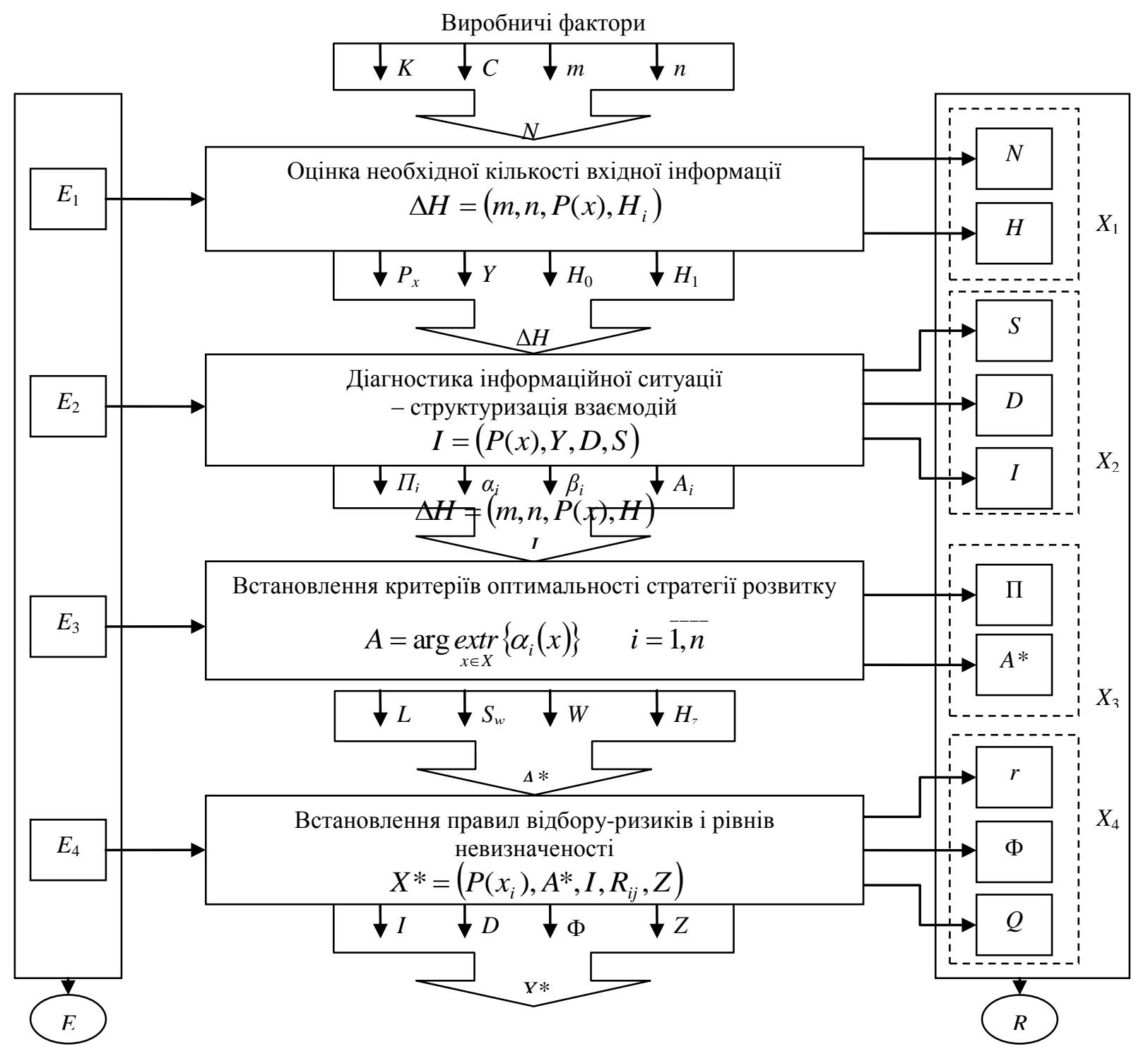

Рис. 2. Формалізація процесу управління інноваційним розвитком виробництва*

*Розроблено автором

Кожна операція управління $X_{1}, X_{2}, X_{3}, X_{4}$ характеризується вхідними і вихідними показниками, внутрішне наповнення яких представлено великими стрілками (рис.2), i параметрами етапів прийняття управлінських рішень $E_{i}$, які характерризують дану операцію, забезпечуючи відповідну результативність іiі виконання.

Після реалізації цих елементарних операцій управління $X_{i}$ відбувається формування показників якості та результативності технологічного процесу інноваційного розвитку виробництва в умовах невизначеності в цілому $R$. При цьому завершенням кожної операції управління $X_{i}$ буде вирішальна функція ідентифікації результатів, яка підлягає вибору на кожному кроці величин це $N, \Delta H, I, A^{*}, X^{*}$, кількісне значення яких визначається станами системи $s \in S$.

В запропонованій схемі формалізації процесу управління інноваційним розвитком виробництва елементи і операції остатнього рівня управління $X_{4}$ залежать від елементів попередніх рівнів $X_{3}$, $X_{2}, X_{1}$. В свою чергу елементи рівня $X_{3}$ залежать від рівнів $X_{2}$ та $X_{1}$. Ці кількісні та якісні показники в цілому формують оптимальну стратегію управління.

Висновки i перспективи подальших досліджень. Запропонована інформаційноентропіна модель кількісної оцінки необхідної вхідної інформації і алгоритм іiі реалізації, дозволяють уточнити основні принципи $\mathrm{i}$ правила формування інформаційного 
забезпечення процесу управління економічного розвитку підприємств. Розрахунки апріорної та апостеріорної інформації і величини ентропії здатні регулювати процес накопичення необхідної кількості інформації при прийнятті управлінських рішень.

Встановлено базові операції підтримки прийняття рішень, які формують оптимальну стратегію управління і включають оцінку потрібної кількості інформації, діагностику інформаційної ситуації, вибір критеріїв оптимальності, становлення правил відбору, вибір критеріїв оптимальності і відображають функціональні особливості виробничої діяльності i сприяють формуванню i нарощуванню іiї інноваційного потенціалу.

\section{ПЕРЕЛІК ВИКОРИСТАНИХ ДЖЕРЕЛ}

1. Макогон Ю.В. Феномен "неопределённости" экономического развития как объективного условия международного взаимодействия / Ю.В. Макогон, Д.Р. Иванова // Вісник ОНУ ім. І.І.Мечнікова. - 2013. - Т.18 - Вип.4/2 - С.15-18.

2. Найт Ф.Х. Риск, неопределенность и прибыль / Ф.Х. Найт [пер. с англ. М.Я. Каждана] - М.: Дело, 2003. $360 \mathrm{c}$.

3. Ларичев О.И. Вербальный анализ решений / О.И. Ларичев - М.: Наука, 2006. - 392 с.

4. Трухаев Р.И. Модели принятия решений в условиях неопределённости / Р.И. Трухаев - М.: Наука, 1981. $-258 \mathrm{c}$.

5. Гусарина Н.В. Использование многокритериальной логики в стратегическом управлении инновационной активностью предприятия / М.В. Шарко, Н.В. Гусарина // Вісник Хмельницького національного університету. Економічні науки. - 2016. - Том 2. - № 3. - С.175-179.

6. Шарко М.В. Формирование инновационного потенциала предприятий - монография. / М.В. Шарко Херсон: ФЛП Гринь Д.С., 2014. - 288 с.

7. Gusarina N. V. Structuriization of the opportunities of information and communitative technologies in the management the development of economic objects / M. Sharko, N. Gusarina // VII International Scientific conference Management and development trends, september 20, 2017, Bangkok. - proceedings of the conference. - Vol. II, Part 1. - P.15-18.

\section{REFERENCES}

1. Makogon Y. (2013) the Phenomenon of "uncertainty" of economic development as an objective condition of international interaction [Bulletin of the Odessa national University im. I. I. Mechnikov], Vol. 18,.4/2, P. 15-18 [in Ukrainian]

2. Knight F. (2003) Risk, uncertainty and profit / [per. from English M. Kazhdan], M.: Case, 360 p. [in Russian].

3. Larichev O. I. (2006) Verbal decision analysis, M.: Science, p. 392 [in Russian].

4. Trochev R. I. (1981) Models of decision making under uncertainty - M.: Nauka, p. 258 [in Russian].

5. Sharko M., Gusarin N. (2016) The use of multi-criteria logic in the strategic management of innovative activity of the enterprises [Herald of Khmelnitsky national University. Economichni science], V. 2, № 3, P. 175-179 [in Ukrainian]

6. Sharko M. (2014) Formation of innovative potential of enterprises. - Kherson: FLP Grin D. S., p. 288 [in Ukrainian]

7. Sharko M., Gusarina N. (2017) Structuriization of the opportunities of information and communitative technologies in the management the development of economic objects [VII International Scientific conference Management and development trends, september 20, 2017, Bangkok], V. II, Part 1, P.15-18. [in China]

Одержано 14.03.2018 p. 